OPEN ACCESS

\title{
A Dilatometric Study of Graphite Electrodes during Cycling with X-ray Computed Tomography
}

To cite this article: H. Michael et al 2021 J. Electrochem. Soc. 168010507

View the article online for updates and enhancements. 


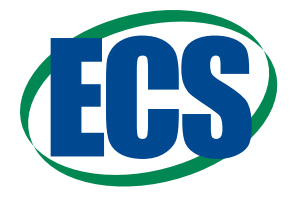

\title{
A Dilatometric Study of Graphite Electrodes during Cycling with X-ray Computed Tomography
}

\author{
H. Michael, ${ }^{1}$ F. Iacoviello, ${ }^{1}$ T. M. M. Heenan, ${ }^{1,2}$ (1) A. Llewellyn, ${ }^{1}$ J. S. Weaving, ${ }^{1}$ R. Jervis, ${ }^{1,2}$ \\ D. J. L. Brett, ${ }^{1,2}$ and P. R. Shearing ${ }^{1,2, z}$ \\ ${ }^{1}$ The Electrochemical Innovation Lab, Department of Chemical Engineering, University College London, WC1E 7JE, United \\ Kingdom \\ ${ }^{2}$ The Faraday Institution, Didcot OX11 ORA, United Kingdom
}

\begin{abstract}
Graphite is the most commonly used anode material in commercial lithium-ion batteries (LiBs). Understanding the mechanisms driving the dimensional changes of graphite can pave the way to methods for inhibiting degradation pathways and possibly predict electrochemical performance loss. In this study, correlative microscopy tools were used alongside electrochemical dilatometry (ECD) to provide new insights into the dimensional changes during galvanostatic cycling. X-ray computed tomography (CT) provided a morphological perspective of the cycled electrode so that the effects of dilation and contraction on effective diffusivity and electrode pore phase volume fraction could be examined. During the first cycle, the graphite electrode underwent thickness changes close to $9 \%$ after lithiation and, moreover, it did not return to its initial thickness after subsequent delithiation. The irreversible dilation increased over subsequent cycles. It is suggested the primary reason for this dilation is electrode delamination. This is supported by the finding that the electrode porosity remained mostly unchanged during cycling, as revealed by X-ray CT. (C) 2021 The Author(s). Published on behalf of The Electrochemical Society by IOP Publishing Limited. This is an open access article distributed under the terms of the Creative Commons Attribution 4.0 License (CC BY, http://creativecommons.org/licenses/ by/4.0/), which permits unrestricted reuse of the work in any medium, provided the original work is properly cited. [DOI: 10.1149/ 1945-7111/abd648]
\end{abstract}

Manuscript submitted September 11, 2020; revised manuscript received December 14, 2020. Published January 7, 2021.

Lithium-ion batteries (LiBs) offer high energy and power densities, and are ubiquitous in portable electronic devices, and increasingly in electric vehicles. ${ }^{1}$ However, the wider deployment of LiBs is hampered by degradation phenomena, ${ }^{2}$ and a key goal for the automotive industry is to understand the degradation mechanisms of $\mathrm{LiB}$ electrodes in order to overcome their limitations in performance and lifetime. ${ }^{3}$ During battery operation, graphite undergoes dilation and contraction; such changes are known to cause electrode strain and electrode particles can undergo swelling or cracking that contribute to the electrode's cumulative degradation. ${ }^{4}$ Understanding how commonly adopted electrodes dilate can be of critical value in improving the durability of these storage devices.

Graphite $\left(\mathrm{C}_{6}\right)$ is the most widely used commercial anode material in LiBs because of its high coulombic efficiency and cycling performance. During cycling, reversible intercalation of $\mathrm{Li}^{+}$ions occurs, resulting in graphite intercalation compounds (GIC) that evolve in stages, with the final stoichiometry of $\mathrm{LiC}_{6}$ obtained on full lithiation. $\mathrm{Li}^{+}$ions are susceptible to being incorporated into graphite with their solvation spheres, and solvated $\mathrm{Li}^{+}$ion intercalation can cause severe exfoliation of graphite particles and result in the destruction of the graphite structure because the Van der Waals forces between the graphene layers of graphite are weak, and solvent molecules are often much larger than $\mathrm{Li}^{+}$ions. ${ }^{5}$ Expansion of graphite's structure can cause deformations as large as $10 \%$ of initial volume when $\mathrm{C}_{6}$ is fully lithiated to $\mathrm{LiC}_{6} \cdot{ }^{6,7}$ However, the entire electrode can increase in volume by $13 \%$ if other contributory factors such as gas evolution ${ }^{8}$ are also taken into consideration.

Since the 1970s, electrochemical dilatometry (ECD) has been used to investigate the swelling or strain associated with host materials due to the intercalation and alloying of guest ions, atoms or molecules. ${ }^{4,9-12}$ The macroscopic dilation and contraction of graphite electrodes during charge/discharge in non-aqueous electrolytes can be recorded using in situ ECD and is therefore complementary to $\mathrm{X}$-ray Diffraction (XRD) analysis, which provides information on the changes in a graphite crystal structure. ${ }^{13}$ Phase transitions that occur in graphite during $\mathrm{Li}^{+}$intercalation, solid electrolyte interphase (SEI) formation and degradation mechanisms can be tracked using $\mathrm{XRD}$, and the associated volume changes monitored with ECD. Numerous articles report the volume changes in graphite

${ }^{\mathrm{z}}$ E-mail: p.shearing@ucl.ac.uk electrodes, during cycling, using in situ ECD, with dimensional changes ranging between $4 \%-10 \%$ owing to differences in electrolyte and cell configuration. ${ }^{4-15}$ However, to the author's knowledge, there is to-date no research corroborating in situ ECD with visual inspection using X-ray computed tomography (X-ray CT) and image-based modelling.

In this study, X-ray CT has been used to reveal vital information about spatial variations in microstructural parameters across the thickness of the electrode. X-ray CT is useful for the inspection of cracks, particle expansion and material composition that contribute to electrode dilation/contraction. ${ }^{16-18}$ The present study uses correlative ECD, scanning electron microscopy (SEM) and X-ray CT to elucidate the mechanisms driving the dilation of graphite electrodes in $\mathrm{LiBs}$ with a view to inhibiting this degradation pathway and possibly predicting its impact on capacity fade. Irreversible dilation of graphite electrodes was recorded during discharge/charge using in situ ECD. During prolonged cycling, the graphite electrode did not return to its original thickness due to changes in the particlebinder matrix and severe delamination in later cycles. Severe delamination of the active material layer from the current collector was confirmed with X-ray CT.

\section{Experimental}

Electrode preparation.-All graphite electrodes examined were obtained as ready-made, calendered electrode sheets from NEI Corporation (NANOMYTE ${ }^{\oplus}$ ). The electrode sheets are composed of synthetic graphite powder on copper sheets with $90 \%$ graphite; $5 \%$ Poly (vinylidene fluoride) PVDF (binder) and 5\% carbon black (conductive additive) by weight. A nominal capacity at $0.1 \mathrm{C}$ of $\geqslant$ $365 \mathrm{~mA} \mathrm{~h} \mathrm{~g}^{-1}$ is reported in the specification sheet. A lithium metal disc (10 mm diameter) provided by MTI Corporation was used as the counter electrode for all the tested cells. Prior to electrochemical tests, the graphite electrodes (10 $\mathrm{mm}$ diameter) were dried overnight at $120{ }^{\circ} \mathrm{C}$ under dynamic vacuum in a Buchi tube and inserted into an argon filled glove box (LABStar, MBraun) with $\mathrm{H}_{2} \mathrm{O}$ and $\mathrm{O}_{2}$ levels kept below $0.5 \mathrm{ppm}$.

Electrochemical dilatometry (ECD).-The in situ ECD experiments were performed with an ECD-3-nano electrochemical dilatometer (El-Cell GmbH, Hamburg). The device measures chargeinduced strain (dilation and contraction) of electrodes with nanometer resolution with a maximum sample size of $10 \mathrm{~mm} \times 1 \mathrm{~mm}$ 
(diameter $\times$ thickness). Displacement signals below five nanometres are detected by the capacitive parallel-plate sensor system.

At the centre of the dilatometer is the electrochemical cell, which is hermetically sealed. To prevent moisture within the electrochemical cell, the dilatometer parts are vacuum dried at $80{ }^{\circ} \mathrm{C}$ in an oven overnight to remove any moisture before the instrument is assembled inside a glovebox. A rigid "T- shaped" frit made of borosilicate glass is fixed in position and acts as a separator between the working and counter electrode. Any charge-induced electrode thickness changes are transmitted towards the sensor/load unit from the upper working electrode that is sealed by means of a thin metal foil; therefore the height change of the working electrode can be determined without any interference from the counter electrode (see Fig. 1). Dimensional changes of the working electrode are detected by a high-resolution capacitive displacement transducer with detection capability ranging from a few nanometres up to $250 \mu \mathrm{m}$.

The bespoke separator for the ECD assembly was soaked in $500 \mu \mathrm{l}$ of electrolyte containing $1 \mathrm{M} \mathrm{LiPF}_{6}$ dissolved in a mixture of ethylene carbonate (EC): ethyl methyl carbonate (EMC) in the ratio $3: 7$ by volume with $2 \%$ (by weight) vinylene carbonate (VC) additive (Soulbrain MI). All gases were pre- evacuated from the pores to ensure proper wetting of the $10 \mathrm{~mm}$ electrode. The glass $\mathrm{T}$ frit position is fixed to ensure only the dilation of the working electrode is recorded.

During formation cycling, the dilatometer "half-cell" was cycled between 0.01-1.0 V under a constant current of $0.097 \mathrm{~mA}$ (an applied rate of $\mathrm{C} / 20$ ) using a single channel battery tester (Reference $600+$ Potentiostat/Galvanostat/ZRA, Gamry Instruments). During multiple cycle parameterisation the half-cell was discharged at a constant current of $0.24 \mathrm{~mA}(\mathrm{C} / 8)$ for 20 cycles. The cycling current was based on the graphite mass $(0.0053 \mathrm{~g}) . \mathrm{C} / \mathrm{x}$ denotes the current required to discharge (or charge) the cell in $\mathrm{x}$ hours.
The cell was held at open circuit for several hours prior to cycling, to allow for baseline stabilization. This initial rest period helped to discern charging induced dimensional changes from the initial creep, which can be induced during charging as a result of the mechanical properties of the working electrode being altered. Thermal contraction or expansion of the electrode and measurement set-up will always influence ECD data, therefore, the ambient temperature was controlled during testing by placing the dilatometer inside an oven at room temperature (approx. $22^{\circ} \mathrm{C}-23{ }^{\circ} \mathrm{C}$ ) during electrochemical tests.

Scanning electron microscopy (SEM).-SEM imaging was performed using an EVO MA 10 microscope (ZEISS, UK) in order to examine morphological changes of pristine and tested graphite electrodes. For SEM imaging experiments, the electrodes were mounted onto stubs using an adhesive carbon tape, and samples were imaged at a working distance of approximately $11-12 \mathrm{~mm}$ and accelerating voltage of $3 \mathrm{kV}$ in back-scattered electron mode. Pristine electrodes were mounted onto conductive stubs without any prior washing. Tested electrodes were rinsed with dimethyl carbonate (DMC) in a glovebox, dried and transferred to the SEM in a vacuum-sealed transfer vial to minimise air or moisture contamination.

X-ray computed tomography (X-ray CT).-_Electrodes were investigated before and after galvanostatic cycling to examine alterations in the electrode microstructure during cycling which can include particle pulverization and electrode swelling due to solvent uptake. 3D images acquired were used to examine crack propagation, particle size distributions, and the possibility of electrode delamination.

An A Series/Compact Laser Micromachining System (Oxford Lasers, Oxford, UK) with an embedded Class 4, $532 \mathrm{~nm}$ wavelength laser was used to prepare samples for X-ray CT. All X-ray imaging

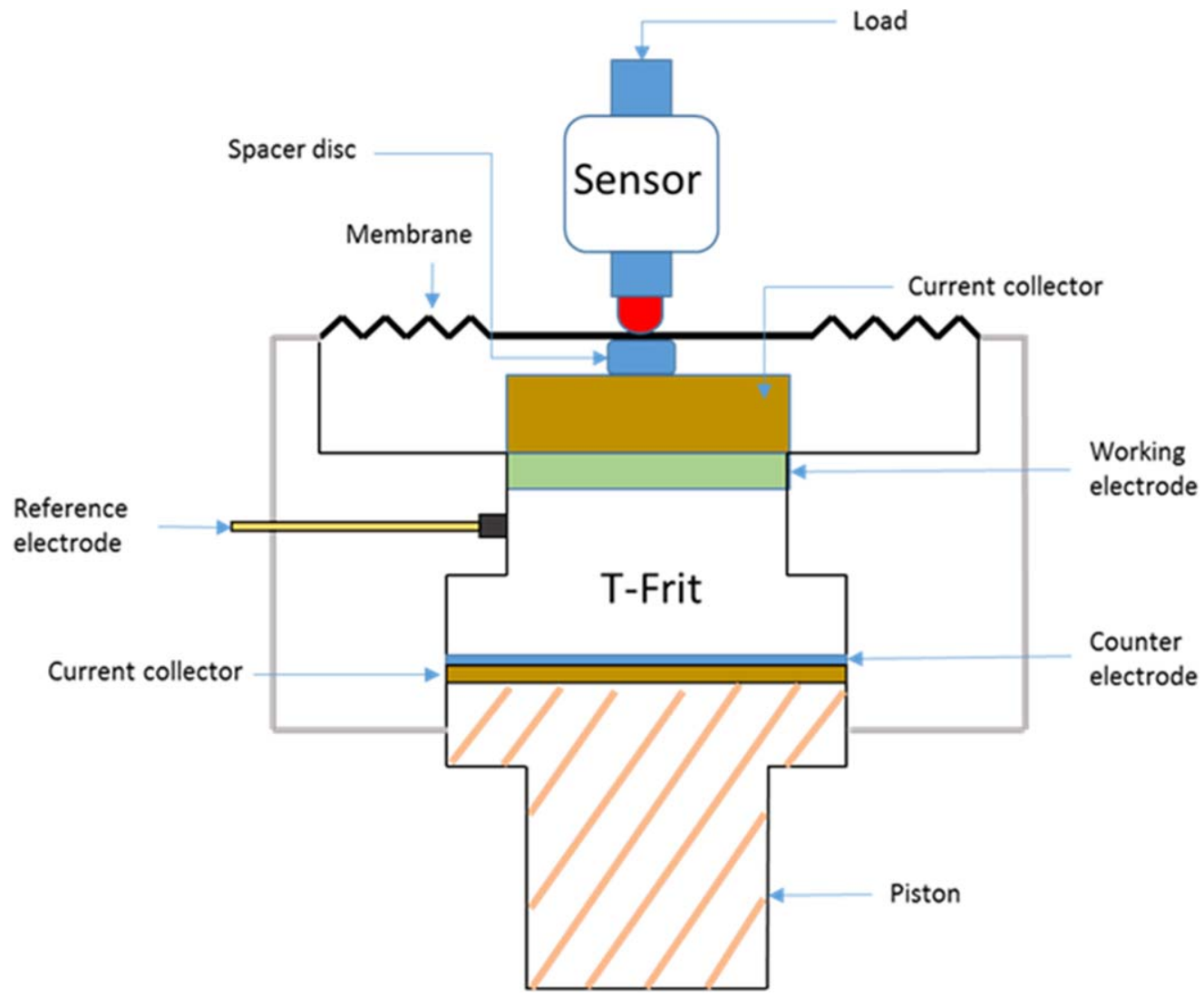

Figure 1. The internal architecture of the dilatometer (ECD-3-Nano, EL-Cell GmbH) device based on a three-electrode geometry and an inductive sensor. Only the dilatation of the working electrode (WE) is recorded because the glass T-frit is fixed in position. 


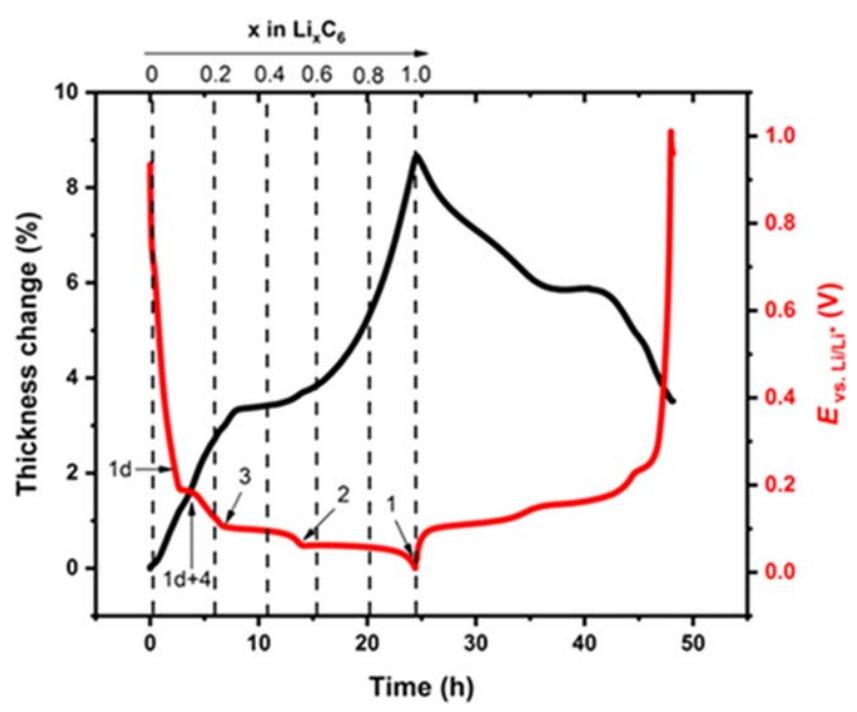

Figure 2. Potential profile and simultaneous dilation record of graphite during the first discharge/charge (formation) with potentials to which graphite phase transitions occur, labelled along the potential curve.

was conducted ex situ on delithiated electrodes using a ZEISS Xradia 520 Versa (Carl Zeiss Microscopy Inc., Pleasanton, USA) micro-CT system.

$\mathrm{X}$-ray CT scans were carried out with an X-ray source tube

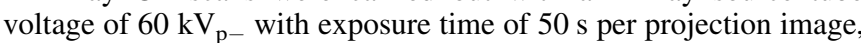
and a total of 1028 projection images were collected per scan using $40 \times$ magnification. Reconstruction of the radiographic data was achieved using a cone-beam filtered back projection algorithm implemented in Zeiss Scout and Scan software resulting in a reconstructed voxel size $(\mu \mathrm{m})$ of $0.203 \times 0.203 \times 0.203$.

\section{Results and Discussion}

Electrochemical dilatometry: single cycle characterisation.Fig. 2 shows the voltage profile and the simultaneous dilation/ contraction recorded for graphite during its first discharge/charge cycle. The initial region from the open circuit potential (OCP) to approximately $0.3 \mathrm{~V} \mathrm{vs} \mathrm{Li} / \mathrm{Li}^{+}$is usually associated with irreversible processes, including SEI formation and possible graphite exfoliation. During discharge in a half-cell configuration (applying a constant negative current), $\mathrm{Li}^{+}$ions intercalate between the graphene layers causing the electrode to dilate, whereas during charging (constant positive current), $\mathrm{Li}^{+}$ions deintercalate causing the electrode to contract, as shown in Fig. 2.

Lithium-graphite intercalation compounds (Li-GICs) are formed on further discharging from OCP. Stages (well-defined periodicity along the $c$-axis consisting of lithium occupied and vacant interlayer spacings) form as a typical feature of Li-GICs. The trend in potential and its associated plateaus can be attributed to stoichiometric domains of pure intercalation phases and the transformation of these phases, as shown by dashed lines in Fig. 2. ${ }^{19}$

The formation of a diluted stage 1 (1d) occurs at potentials $<0.3 \mathrm{~V} \mathrm{vs} \mathrm{Li} / \mathrm{Li}^{+}$. The first potential slope is immediately followed by a plateau attributed to the transformation of diluted stage $1\left(\mathrm{LiC}_{6}\right)$ into stage 4 as $\mathrm{LiC}_{72}(1 \mathrm{~d}+4)$. Stage $3\left(\mathrm{LiC}_{36}\right)$, stage $2\left(\mathrm{LiC}_{12}\right)$ and stage 1 are subsequently formed. The dilation plateau is attributed to the ordering of $\mathrm{Li}^{+}$ions during the formation of stage $2 .{ }^{20}$

Dimensional changes of the electrode are minimal between $\mathrm{x}=$ 0.2 and 0.6, which is in agreement with XRD measurements that detect small changes in volume between these phase transitions. ${ }^{21-25}$ The dilation slope increases most sharply during the beginning of stage 1 formation, (the reverse of which is also observed during delithiation from stage 1). The interlayer d-spacing is significantly larger during the $\mathrm{LiC}_{6}$ phase than the $\mathrm{LiC}_{12}$ phase. The slope corresponding to thickness change increases most when the $\mathrm{LiC}_{6}$ phase is present and a plateau separates the two slopes during charging, where the thickness stays nearly constant. ${ }^{26}$ The interlayer $\mathrm{d}$-spacing decreases significantly in cases where $\mathrm{x}<0.3$ in $\mathrm{Li}_{\mathrm{x}} \mathrm{C}_{6}$. Consequently, the unit cell also decreases, which in turn leads to a decrease in the electrode thickness. ${ }^{27}$ The thickness changes during $\mathrm{Li}^{+}$intercalation/deintercalation are attributed to crystallographic pathways (Van der Waals gaps between the graphene sheets that allow for $\mathrm{Li}^{+}$diffusion) during discharge/charge. ${ }^{28}$ The thickness changes observed and differences in d-spacings of the graphite lattice are in accordance with findings reported by Rieger et al. ${ }^{27}$

As illustrated in the detailed view in Fig. 2, the dilation of the electrode starts above $0.18 \mathrm{~V}$ vs $\mathrm{Li} / \mathrm{Li}^{+}$, in the region of $\mathrm{SEI}$ formation, and before the actual intercalation of desolvated $\mathrm{Li}^{+}$is observed. The electrode undergoes an overall irreversible thickness change of 3\% after its first full cycle despite delithiation. Yu et al reported similar observations when studying the dilatometric mechanism of silicon electrodes. ${ }^{29}$ They suggested this dilation was due to particle rearrangement in the binder matrix despite full delithiation. Although their study used silicon electrodes which are known to undergo substantial morphology change during cycling, the overall dilation trend described can also be applied to graphite electrodes: as the graphite particles swell during $\mathrm{Li}^{+}$intercalation, causing the graphene sheets to push apart, the particles are relocated in the binder matrix. Subsequent contraction causes the sheets to shrink, but the particles do not return to their original positions with respect to the binder, causing empty voids to emerge and increasing the electrode's thickness. ${ }^{29}$

Binders such as PVDF influence the tensile strength of electrodes and adhesion strength of the active material to the current collector. ${ }^{30}$ This is particularly important in systems with electrodes that undergo large dimensional changes. $\mathrm{Li}$ et al. investigated the effect of the binder on electrode strain in Li-sulfur battery electrodes using a similar experimental set-up. ${ }^{11,12}$ It is likely that without PVDF, irreversible dilation would be even higher with each cycle, with more severe thickness variations and more detrimental capacity fading. Ultimately, complete electrode delamination could be expected. In contrast, carbon black serves as a conductive additive, maintaining an electronic pathway between graphite particles and the current collector. No carbon black would likely result in more electrically isolated particles, which cannot contribute to charge/ discharge or capacity loss. ${ }^{31,32}$ Consequently, if no carbon black were present, smaller thickness changes would be expected. Confounding issues associated with current collector delamination are discussed in the subsequent section.

Electrochemical dilatometry: multiple cycle characterisation.ECD was applied to characterise the changes in electrode thickness across numerous cycles as shown in Fig. 3. The trend in thickness change exhibited is in agreement with analytical predictions from literature as the graphite electrode's cumulative irreversible strain increases with additional cycles. ${ }^{30,33}$ The fastest change in thickness occurs during the first three cycles, which can be attributed to morphological changes and continued formation of SEI. The small changes in electrode thickness that occur after the third cycle suggests that graphite particles that dilate during $\mathrm{Li}$ intercalation fill electrode pores: as particles swell to fill the empty voids there is a hysteresis in the thickness changes recorded, as the changes occur undetected by the dilatometer. ${ }^{34}$ It is only when the particles displace vertically away from the electrode, that height changes $(\Delta h)$ are detected. Fig. 3 illustrates the thickness change associated with a "full-cycle" dilation.

Graphite's dilation/contraction is consistent for approximately 14 cycles. The electrode is shown to periodically "breathe" with each cycle. It has been suggested that this behaviour is due to graphite particles exfoliating to crystalline platelets that do not delaminate from the electrode. ${ }^{35}$ Graphite phase transitions are a lot more visible in the earlier cycles, and $\mathrm{Li}^{+}$intercalation is affected as the number of cycles increases and the capacity fades. Electrode fracture can 
(a)

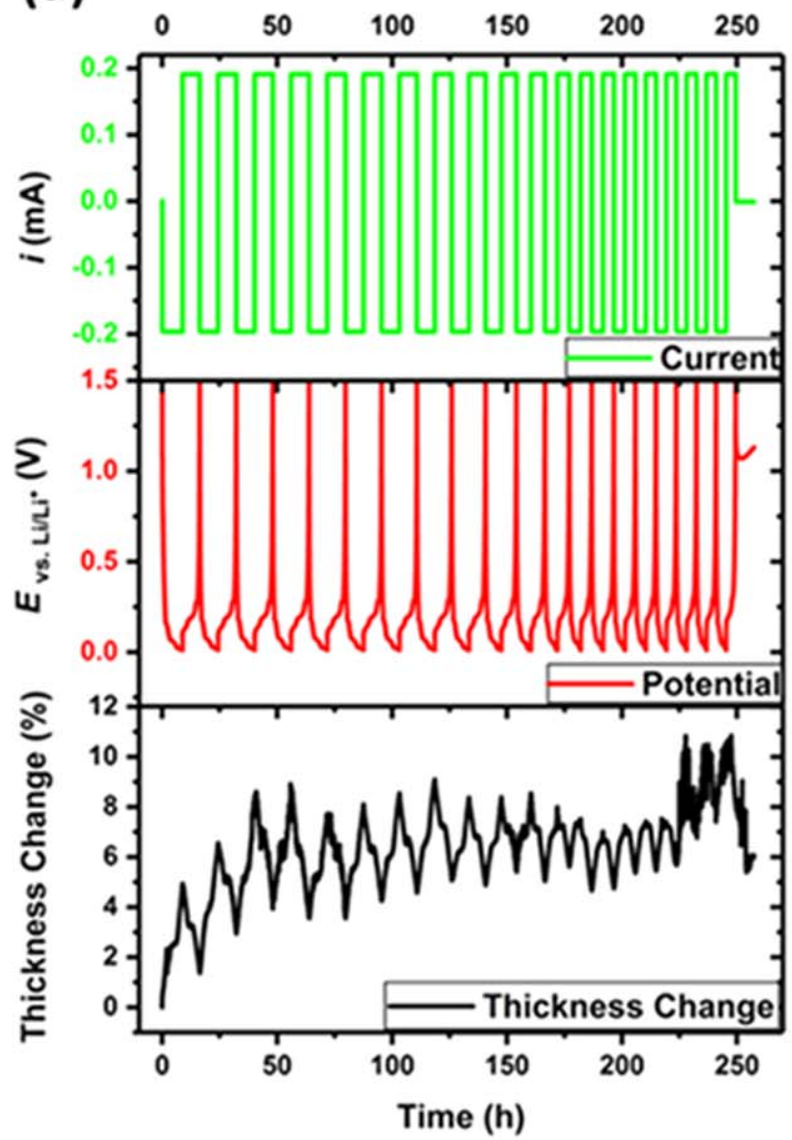

(b)
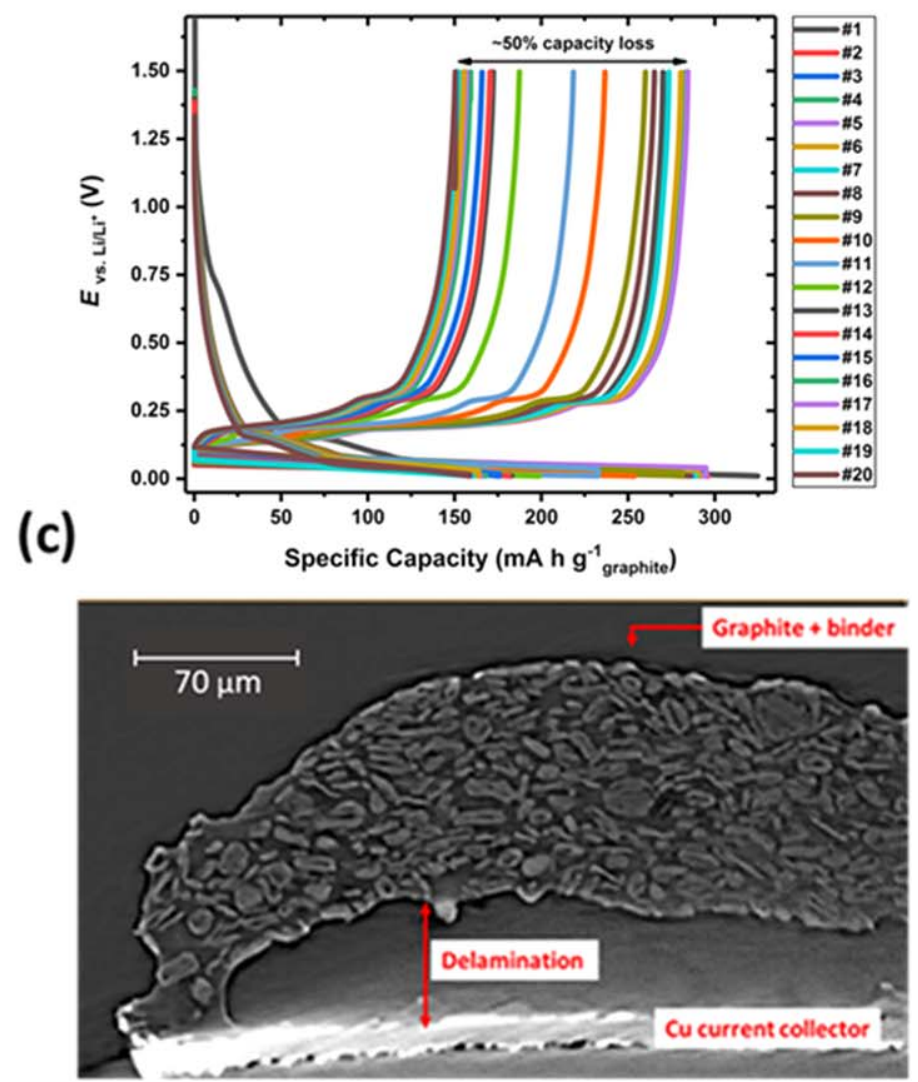

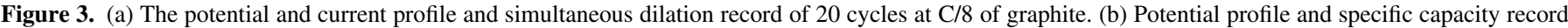

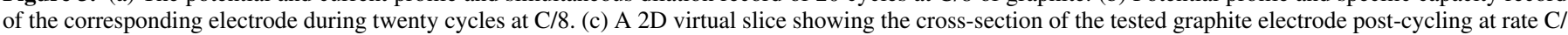
8 for 20 cycles. The image was acquired using X-ray computed micro-tomography.

lead to capacity loss when it causes the active particles to no longer be electrically connected to the current collector, each other, or the binder matrix and arises when the electrode undergoes dilation/ contraction during charge/discharge. ${ }^{36}$ For instance, stage 1 formation is suppressed after approximately 11 cycles, suggesting $\mathrm{Li}^{+}$ intercalation into graphite becomes affected. The shape of cycles 12 -17 would suggest full $\mathrm{Li}^{+}$intercalation into graphite no longer occurs and this coincides with the largest fall in electrode capacity occurring between cycle 11 and 12 of $200 \mathrm{~mA} \mathrm{~h} \mathrm{~g}^{-1}$ down to $160 \mathrm{~mA} \mathrm{~h} \mathrm{~g}^{-1}$ (see Fig. 3b). Subsequent cycling after cycle 12 shows a largely suppressed peak, where stage 1 formation is expected to occur. The inability of $\mathrm{Li}^{+}$ions to fully intercalate into graphite could be a result of lithium plating, as the cell is cycled to very low voltages. Literature has shown lithium plating can occur when graphite's surface potential falls below $0 \mathrm{~V}$ vs $\mathrm{Li} / \mathrm{Li}^{+} .{ }^{37}$ However, this is an unlikely cause in this scenario and there is no evidence of lithium plating when the electrode is visually inspected during cell disassembly. ${ }^{38}$

The distorted signal in the final three cycles could be attributed to electrode delamination, which is confirmed to occur by post-mortem $\mathrm{X}$-ray CT (see Fig. 3c). As the active layer delaminates from the current collector, the sensor records this as height increases that can be mistaken for electrode dilation. Furthermore, the fragility of the active layer may cause it to rise and fall into the empty void, between the active layer and copper current collector, causing height reductions in the recorded data, which can be mistaken for electrode contraction. Thus, details of graphite's dimensional changes may be lost during later cycling.

It is possible that sample preparation ahead of X-ray CT played a role in electrode delamination during cleaning and handling.
However, the distorted signal recordings during the final cycles suggest delamination occurred during cycling; this may also be responsible for the capacity fade in later cycles. Continued cycling could have resulted in complete cell failure, as the active layer is very loosely connected to the current collector on disassembly (see Fig. 3c).

The practical capacities recorded during ECD measurements fade a lot faster on cycling than equivalent coin cell assemblies. The difference in cell design is likely to be a cause of the rapid capacity fading, particularly as a large borosilicate glass T-frit is used as a separator, causing $\mathrm{Li}^{+}$diffusion between electrodes to become a critical limiting factor. The difference in capacity values measured for this ECD set-up compared with coin cells is known from previous reports. ${ }^{35,39,40}$ It is possible that the rate is severely hampered by using the large separator, and that even a relatively slow rate of $\mathrm{C} / 8$ has enough overpotential to mean that full capacity is not reached. The rapid capacity fading can have a significant impact on the thickness changes recorded because cycling, being diffusion limited, means less of the graphite electrode can be accessed for $\mathrm{Li}^{+}$intercalation. Thus, smaller thickness changes and fewer crystal structure changes of graphite are recorded when compared to slower C-rates. In addition, the electrode delamination that occurs in later cycles causes capacity loss because connected active material is lost. In an ideal cell configuration, it is generally not expected that higher C-rates would be accompanied by smaller thickness changes associated with $\mathrm{Li}^{+}$intercalation. Neither is it expected that thickness changes are more severe at higher C-rates. Mass transport limitations of the T-frit separator can lead to significant overpotential with some excess SEI formation/lithium 
plating on subsequent cycles that would not occur in a real cell environment at lower C-rates.

Two parameters can be used for multiple cycle characterisation of the thickness changes undergone by the tested electrode as shown below:

The height change $(\Delta \mathrm{h})$ is used to calculate percentage thickness change of the electrode by using Eq. 1:

$$
\text { Thickness change }(\%)=\frac{h(t)-h_{i}}{h_{i}} \times 100
$$

where $h_{\mathrm{i}}$ is the initial thickness of the electrode and $h(t)$ is the thickness of the electrode measured continuously during cycling, resulting in a thickness change-time curve. Values for $\Delta l$ initially increase during the first few cycles and then decrease upon further cycling (see Fig. 4). The capacity drops markedly after the first few cycles, and thus the full extent of thickness change is not accessed for the entire electrode. The $\Delta \mu$ values always increase as cycling progresses but they increase more sharply during the first few cycles, most likely due to continued SEI formation. The initial net increase after two cycles is approximately $3 \%$ and is likely related to SEI formation and the exfoliation of graphite particles. ${ }^{33,41}$ Therefore, the first two cycles leading to an overall thicker electrode can be seen as "activation cycles". ${ }^{35}$ The electrode dilation increases more gradually during subsequent cycling-taking approximately eight cycles to reach a further $3 \% \Delta \mu$ - and is associated with a significant change in electrode porosity, allowing particles to rearrange themselves in the electrode before the electrode vertically displaces.

It is unclear if lateral expansion of the graphite electrode has the potential to be a complication using this cell configuration as the inner diameter of the EL-Cell is approximately $10 \mathrm{~mm}$ and the diameter of the WE is $10 \mathrm{~mm}$. If we assume that lateral expansion occurs, this expansion could be forced to displace vertically on contact with the inner walls of the frit flange. This could result in higher thicknesses around the outer perimeter of the electrode. However, as the sensor tip is placed centrally above the working electrode, it does not measure thickness change around the outer perimeter of the electrode and thus this lateral expansion might not be recorded. It is possible that uneven thickness variations of the electrode after numerous cycles could contribute to the capacity fading observed after numerous cycles and subsequent electrode delamination.

ECD has proven to be a useful tool to elucidate which phase transitions are suppressed during later cycles, by analysing how electrode thickness changes during each cycle. In addition to (a)

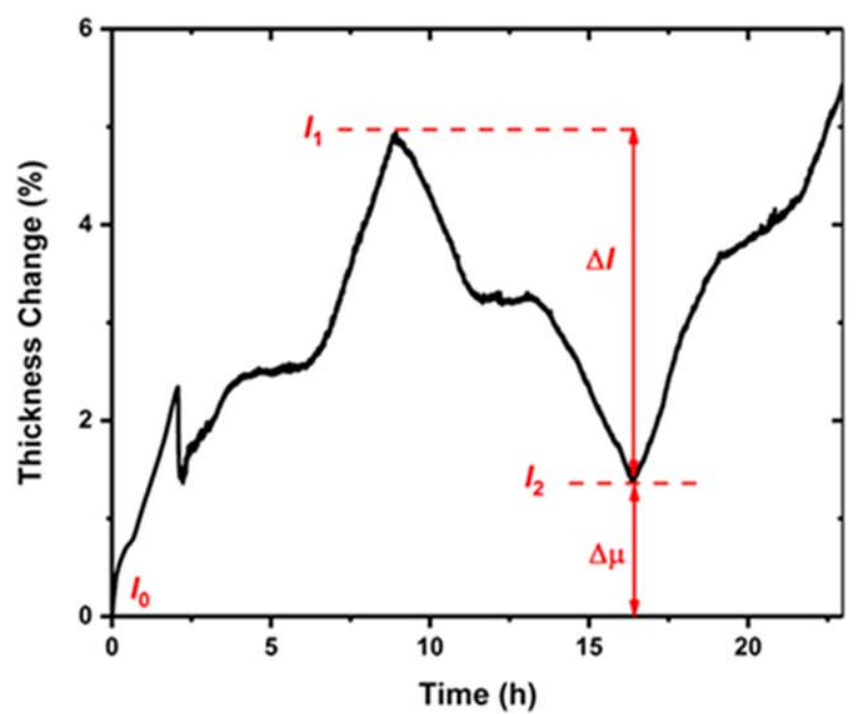

(c)

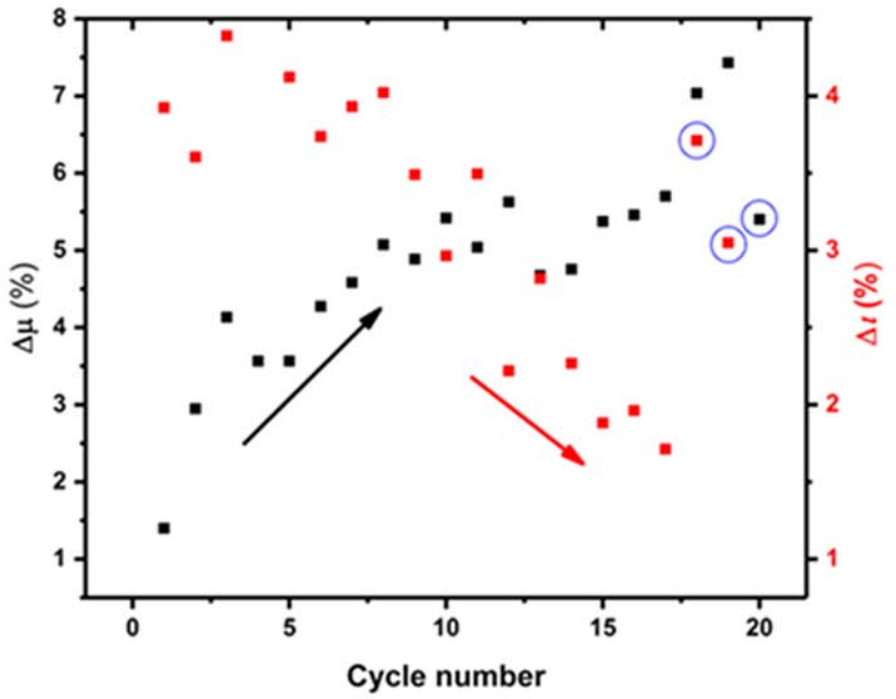

Active material + Binder * Conductive additive

The current collector
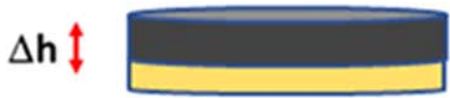

$\mathrm{l}_{0}: 79 \mu \mathrm{m}$

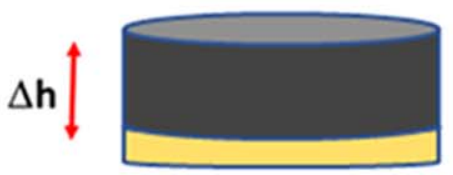

$$
\mathrm{l}_{1}: 82 \mu \mathrm{m}
$$
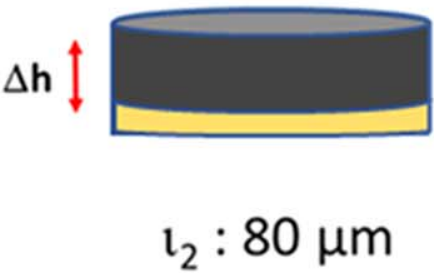

Figure 4. (a) Schematic for calculating $\Delta \mu$ and $\Delta \mathrm{I}$ and the relationship between the two parameters across one cycle. $\Delta \mu$ refers to the irreversible thickness change of the graphite electrode between the initial thickness $(79 \mu \mathrm{m})$ of the electrode and its final thickness, i.e., $\Delta \mu=\mathrm{I}_{2}-\mathrm{I}_{0}$. $\Delta \mathrm{I}$ refers to the change in thickness within one cycle between a lithiated and delithiated state, i.e., $\Delta \mathrm{I}=\mathrm{I}_{1}-\mathrm{I}_{2}$; (b) The change in $\Delta \mu$ and $\Delta \mathrm{l}$ during 20 cycles at $\mathrm{C} / 8$ for the graphite electrode. The circled data points represent anomalous results. (c) shows a sketch of the height changes $(\Delta \mathrm{h})$ of the electrode as it vertically displaced during one cycle. Height changes $(\Delta \mathrm{h})$ are used to calculate thickness changes $(\%)$. 
electrode delamination, side reactions could be occurring that alter the height changes recorded and cause the capacity to rapidly fade. For example, multiple parallel reactions between the active material and electrolyte, electrolyte decomposition, passive film formation, active material dissolution and other phenomena. ${ }^{42}$ Multiple factors can play a role in the dimensional changes recorded during multiple cycle characterisation at higher $\mathrm{C}$-rates. Although dilatometry is a powerful technique for recording overall dimensional changes of the graphite electrode, other techniques are needed in tandem to elucidate the causes of these changes.

Morphological characterisation.-SEM was used to compare the surface morphology of a pristine graphite electrode with the tested electrode that was cycled at $\mathrm{C} / 8 \mathrm{C}$-rate for 20 cycles (see Fig. 5).

The surface morphology of pristine and cycled graphite is strikingly different as shown in Fig. 5 despite the cycled electrode being rigorously washed to ensure no electrolyte salts would appear during surface evaluation. However, it is possible, that lithium deposits and $\mathrm{LiPF}_{6}$ salts were not removed entirely during the washing process. Sections of the tested electrode appear elevated at lower magnifications (see Fig. 5f), and significant fragmentation can be observed in these areas (see Figs. 5d-5f).

Elevated sections of the electrode and fragmentation are indicators of severe degradation. Fragments are segments of the electrode and are likely to consist of graphite flakes, removed from the electrode during cycling. Gu et al. suggest that large changes in the lattice parameters associated with phase changes can lead to the fracture of particles and the loss of contact from the electrode matrix. ${ }^{43}$ The graphite particles are highly ordered before cell cycling with no evidence of fragmentation. There is however, a random distribution and large number of fragments on the electrode surface post- cycling. For instance, a graphite particle in Fig. 5e shows a high abundance of fragments on its surface, whereas particles residing further into the bulk appear to have fewer fragments on their surface. There is a possibility that graphite particles that are more elevated have a greater likelihood of these fragments adhering to their surface than particles residing closer to the current collector.

Whilst the micrographs are useful for showing qualitative structural information, their main drawback is that they do not provide quantitative information on inherently three-dimensional structural parameters such as tortuosity and effective diffusion. ${ }^{44}$

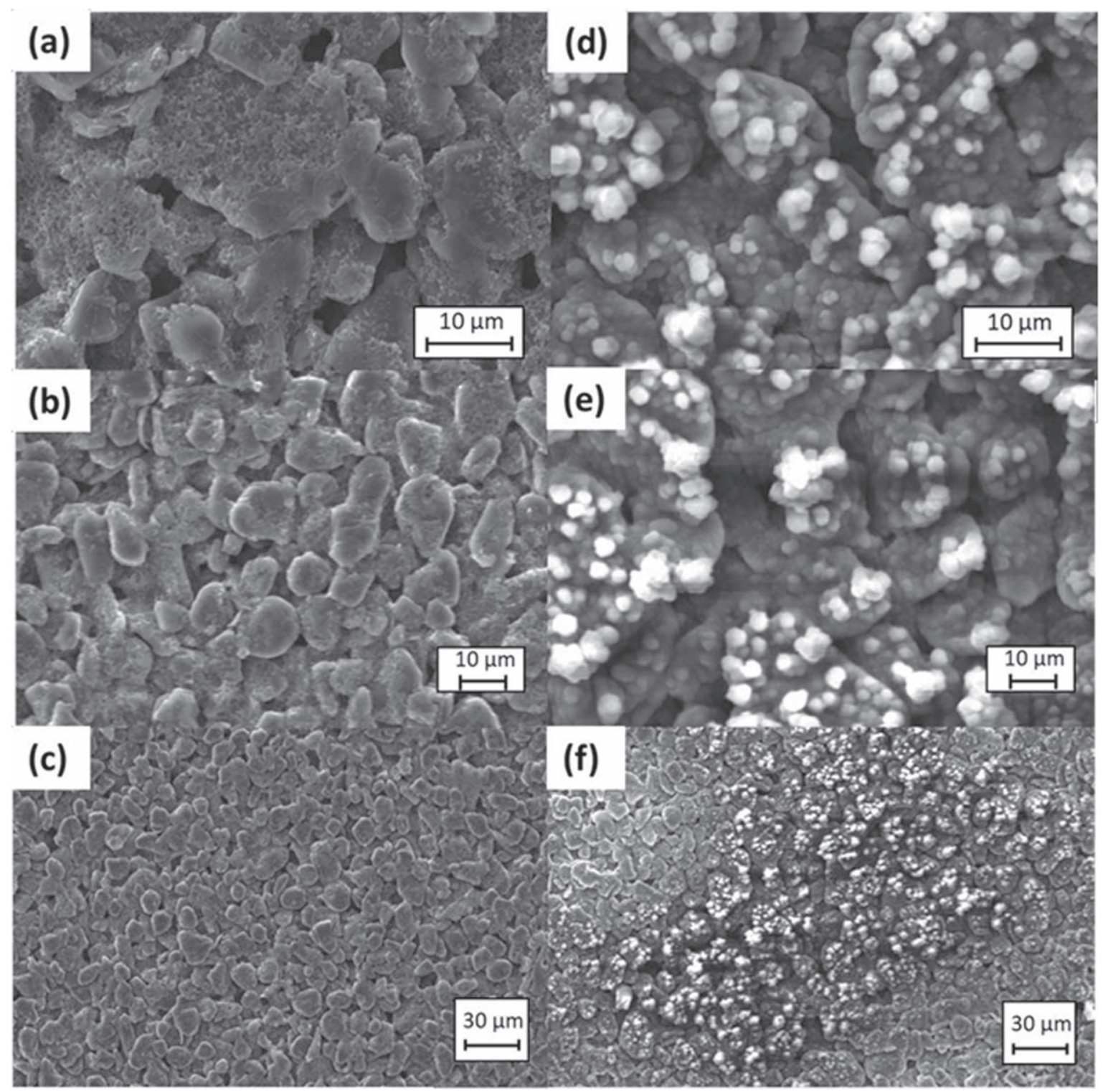

Figure 5. SEM images of the surface structures of the evaluated pristine (a)-(c) and cycled (d)-(f) graphite electrodes at C/8 rate for twenty cycles: (a) and (d)

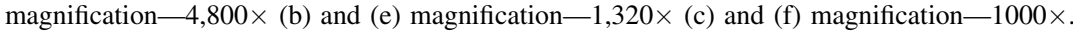


These parameters directly influence the performance of the electrode in the cell; thus, X-ray CT was also used to evaluate differences in morphology of the fresh and cycled electrode. 3D visualizations of reconstructed tomograms were processed using Avizo 9.0 (Thermo Fisher Scientific) (see Fig. 6).

The micro-CT cross-sectional orthoslices shown in Figs. 6a and $6 \mathrm{~d}$ were considered reasonably representative of all orthoslices obtained for each electrode, in addition, these correspond to approximately middle slice numbers for each electrode; their segmentations are shown in Figs. $6 \mathrm{~b}$ and $6 \mathrm{e}$ respectively for illustrative purposes. The volume rendering of the solid phase in the pristine and cycled electrode shown in Figs. $6 \mathrm{c}$ and $6 \mathrm{f}$ visually demonstrates that the electrode's solid phase volume fraction does not significantly increase as a result of cycling, which is quantified in Table I. The solid phase can also be referred to as "the active phase" because it's composed of binder, additive and graphite particles.

The electrode is not expected to undergo large changes in pore phase volume fraction after 20 cycles at a relatively slow C-rate of $\mathrm{C} / 8$. However, some graphite particles have undergone significant cracking. Particles (blue) appear smaller in Fig. 6e compared to particles in Fig. 6b, which is likely to be due to fragmentation. Furthermore, significant electrode delamination is shown in Fig. 6j corresponding to the cycled electrode. In contrast, the uncycled electrode in Fig. 6i shows how the electrode should look when no delamination is present. The active layer is entirely adhered to the current collector. It is highly likely that this electrode delamination contributed to the distorted signal recordings and large thickness changes recorded during later cycling.

The particle size distributions (Figs. 6k and 61) extracted from the volume renderings of the pristine and cycled graphite electrodes are comparable, providing some validation of the particle sizes in the 2D orthoslice datasets. The graphite particles of the pristine and cycled electrode are separated and identified as shown in Figs. $6 \mathrm{~g}$ and $6 \mathrm{~h}$. According to the distribution of particle volumes, most particles in the pristine electrode have a volume between $500 \mu \mathrm{m}^{3}$ to $1000 \mu \mathrm{m}^{3}$. In the case of the cycled electrode, most particles have a volume less than $500 \mu \mathrm{m}^{3}$. In addition, larger particles reside in the pristine electrode compared to the cycled electrode, with some having a particle volume $\sim 5000 \mu \mathrm{m}^{3}$. The largest particles in the cycled electrode are between $2500-3000 \mu \mathrm{m}^{3}$. The presence of larger particles in the pristine electrode suggest smaller pores; smaller particles in the cycled electrode suggest larger pores. Electrolyte transport occurs through the electrode pores, carbon and binder pores. ${ }^{45}$ It is likely that electrolyte can diffuse more readily through larger pores. For ease of reference Fig. 7 depicts the key findings from the different methodologies used in this work.

Image-based modelling.-Modelling simulations were used to explore how continuous dilation and contraction impact various transport parameters in the electrode. The MATLAB plugin TauFactor was used to calculate transport parameters such as phase volume fraction, tortuosity factor $(\tau)$ and effective diffusivity $\left(\mathrm{D}^{\mathrm{eff}}\right)$. Geometric tortuosity $(\zeta)$ is a measure of the ratio between a path length from point $\mathrm{A}$ to $\mathrm{B}$ in a $3 \mathrm{D}$ microstructure $\left(\mathrm{L}_{\mathrm{eff}}\right)$, and the path length as a straight path distance from point A to B $(L)$.

$$
\zeta=\frac{L_{e f f}}{L}
$$

The tortuosity factor is an estimate of the diffusive or conductive transport flux across one phase in a 3D microstructure, divided by the transport flux for straight-through paths. The tortuosity factor $(\tau)$ is therefore defined as the square of the geometric tortuosity $(\zeta){ }^{46}$

$$
\tau=\left(\frac{L_{e f f}}{L}\right)^{2} \approx \zeta^{2}
$$

Diffusive tortuosity factor, defined as the TauFactor, solves the steady-state diffusion equation between two Dirichlet boundary conditions for a binarized volumetric data set. ${ }^{45,47}$ Only subvolumes that statistically represent the entire electrode volume were considered, as confirmed by a representative volume element analysis.

TauFactor recorded a pore phase volume fraction of $42.0 \%$ in the pristine electrode, and a pore phase volume fraction of $41.6 \%$ in the cycled electrode. It is generally expected that the pore phase volume fraction would remain very similar after only 20 cycles at a slow Crate of $\mathrm{C} / 8$. Taiwo et al. also found a graphite electrode to have a pore phase volume fraction of $42 \%$ prior to cycling using TauFactor simulations. $^{44}$

Tortuosity factor values are similar for both electrodes in the $\mathrm{x}-$, $y$-directions of the analysed volume. Interestingly, this is in stark contrast to calculated values in the z-direction which are significantly more tortuous. The highest value of tortuosity factor of 3.28 is recorded in the $\mathrm{z}$-direction in the cycled electrode. The fact that the tortuosity factor is also highest for the pristine electrode in the $\mathrm{z}$ direction suggests that cycling is not responsible. The z-direction represents the through plane orientation in the electrode and so the tortuosity is expected to be largest here due to the arrangement of the platelet shape particles. The isotropic recordings for the $\mathrm{x}$ - and $\mathrm{y}$ directions are likely due to alignment of the platelet particles within the electrode, caused by packing ordering and calendering.

Results in Table I show that the pore phase is less tortuous in the cycled electrode compared to the pristine electrode in the $\mathrm{x}$ - and $\mathrm{y}$ directions. A larger value of tortuosity factor corresponds to a more tortuous path. Particle cracking could allow for $\mathrm{Li}^{+}$ions to diffuse through the electrode with less tortuous diffusion pathways. In addition, empty voids in the pore phase which reduce tortuosity could arise due to cycling. Directional percolation is slightly higher in the cycled electrode which suggests that more pores are connected and is consistent with a lower tortuosity factor.

\section{Conclusions}

Dimensional changes of graphite electrodes have been investigated using physical and electrochemical techniques to explore the effect that continuous dilation and contraction has on the overall electrode performance. In-situ ECD was successfully used to reveal an irreversible dilation of a graphite electrode during discharge/ charge. The tested graphite electrodes were shown to dilate with $\mathrm{Li}^{+}$ intercalation in the standard operating window and by approximately $9 \%$ at complete lithiation to $\mathrm{LiC}_{6}$ during an SEI formation cycle. Cycled electrodes did not return to their original thickness due to severe delamination and changes in the particle-binder matrix which were confirmed with X-ray CT.

Graphite's dilation/contraction was replicated and consistent across numerous cycles with periodic breathing of the electrode, evident between successive cycles. However, the scale of thickness change was consistently smaller at a faster C-rate. Thus, the findings would suggest that the applied C-rate has an influence on dilatometric measurements. The electrode underwent a thickness change of $3 \%$ after a single cycle at $\mathrm{C} / 20$ compared to around $7 \%$ after 20 cycles at a faster $\mathrm{C}$-rate. At faster $\mathrm{C}$-rates, cycling became diffusion limited, and therefore fewer dimensional changes due to $\mathrm{Li}^{+}$ intercalation and crystal structure changes of the graphite were recorded.

Dilatometry is undoubtedly a powerful technique for measuring the dimensional changes of a single electrode during galvanostatic cycling. However, using other techniques alongside dilatometry can shed light on the structural factors which accompany the dimensional changes, thus providing a much richer explanation of what is happening during cell cycling.

SEM was used to compare the changes, caused by cycling, in surface morphology of a pristine and cycled electrode. A striking difference was observed; deposits seemed to adhere to the surface of the cycled electrode.

For the first time known to the authors, X-ray CT was used alongside in situ ECD and SEM to provide additional visual 


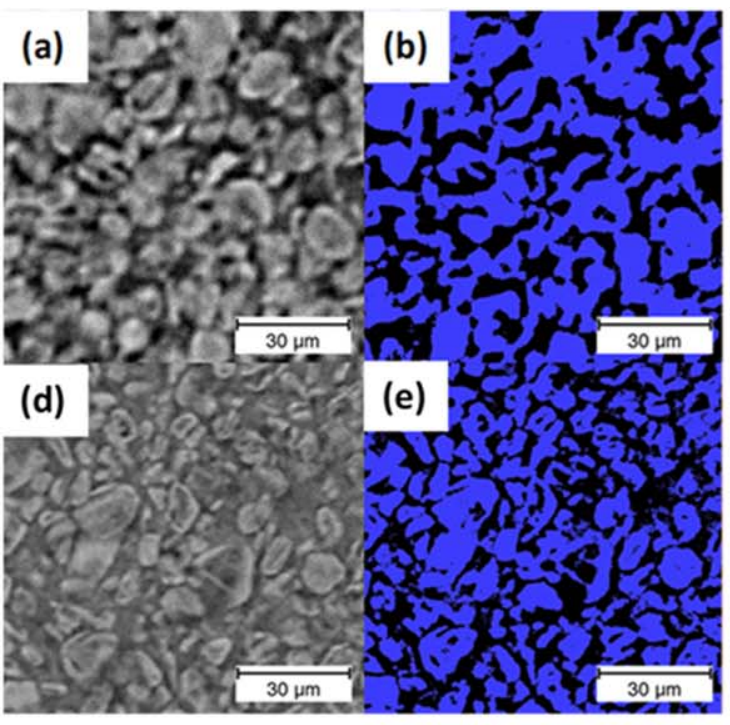

(g)

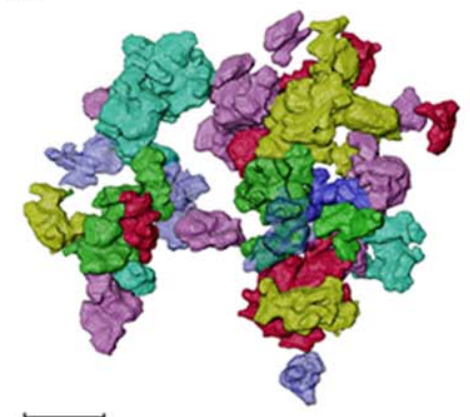

$\stackrel{20 \mu \mathrm{m}}{20}$

(i)

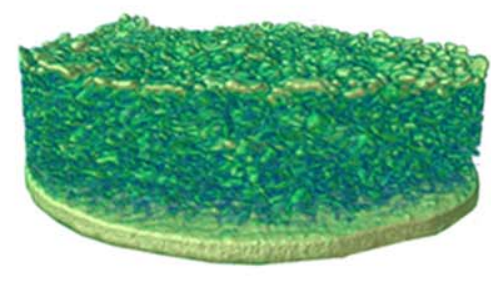

$100 \mu \mathrm{m}$

(k)

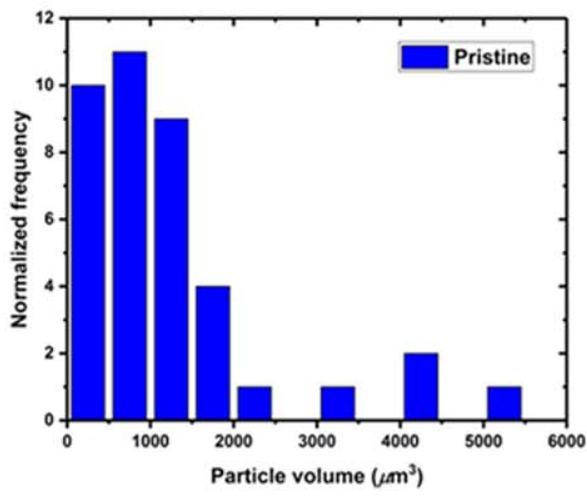

(c)

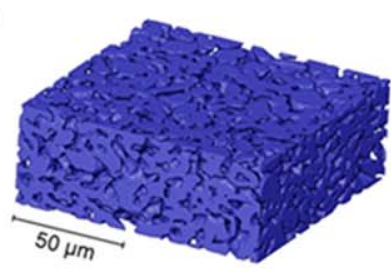

(f)

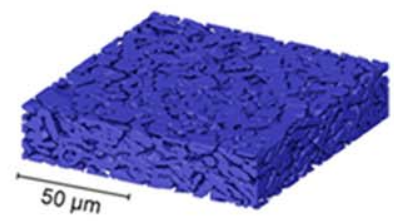

(h)

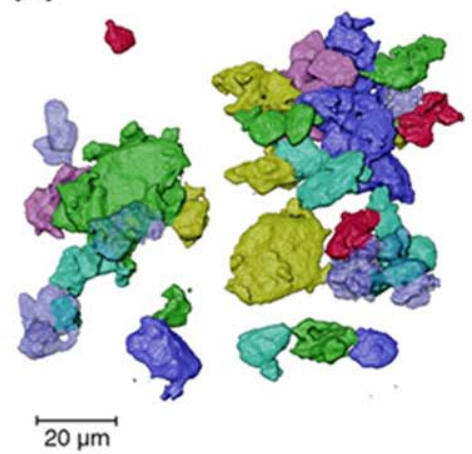

(j)

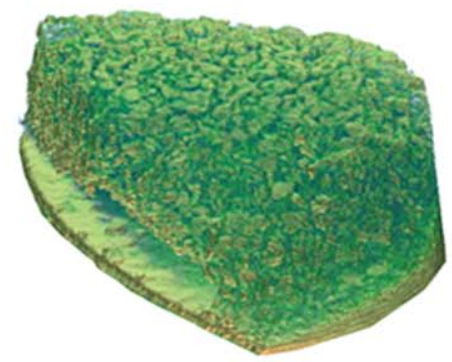

(I)

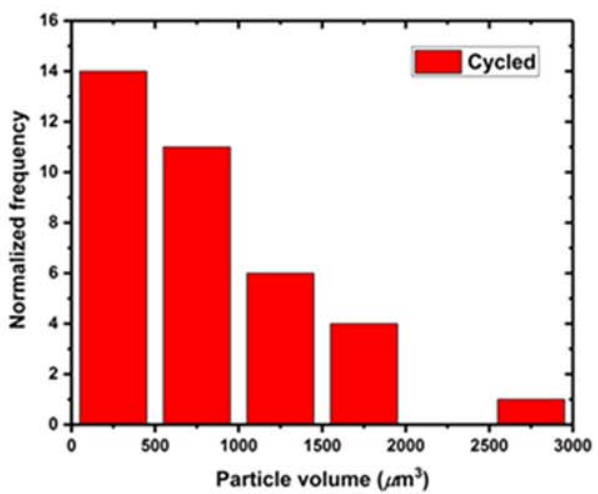

Figure 6. (a) Micro-CT images of the pristine graphite electrode (a) and cycled electrode (d) showing a cross-sectional orthoslice through the thickness of the sample in the xy phase. The particle (blue)-pore (black) distribution shown in (b) and (e) after segmentation correspond to the data shown in (a) and (d). 3D volume rendering of the solid phase (blue) of the pristine (c) and cycled graphite electrode (f) after reconstruction and segmentation. Pristine and cycled electrode particles after algorithmic particle separation and identification are shown in (g) and (h). 3D reconstruction of the entire pristine (i) and cycled electrode (j) show the current collector and active layer respectively. Volumetric distribution of electrode particles in the pristine electrode $(\mathrm{k})$ and cycled electrode (1). Data shown in (a), (b), (c), (g), (i) and (k) are of the pristine graphite electrode and (d), (e), (f), (h), (j) and (l) are for the cycled graphite electrode at a rate of $\mathrm{C} / 8$ for 20 cycles. corroborative evidence of the morphological changes that occur during cycling of $\mathrm{Li}$ - ion batteries and explain changes in dilatometric measurements. The X-ray CT revealed that cycling caused the graphite particles to fragment and significant electrode delamination occurred, according to the volume rendered images of the pristine and cycled electrode. X-ray CT simulations showed similar 


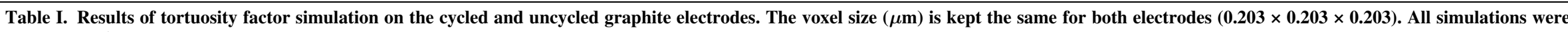
conducted with respect to the pore phase.

Graphite electrode

Solid phase volume fraction (\%)

Pore phase volume fraction (\%)

Directional percolation (\%)

Tortuosity factor $(\tau)$, in direction

Pristine (uncycled) 58.0

58.4

42.0

99.1

99.4

\begin{tabular}{ccc}
\multicolumn{3}{c}{ Tortuosity factor $(\tau)$, in direction } \\
\hline $\mathrm{X}$ & $\mathrm{Y}$ & $\mathrm{Z}$ \\
\hline 2.17 & 2.13 & 3.02 \\
2.12 & 1.97 & 3.28
\end{tabular}

Tested (cycled)

41.6

3.28 


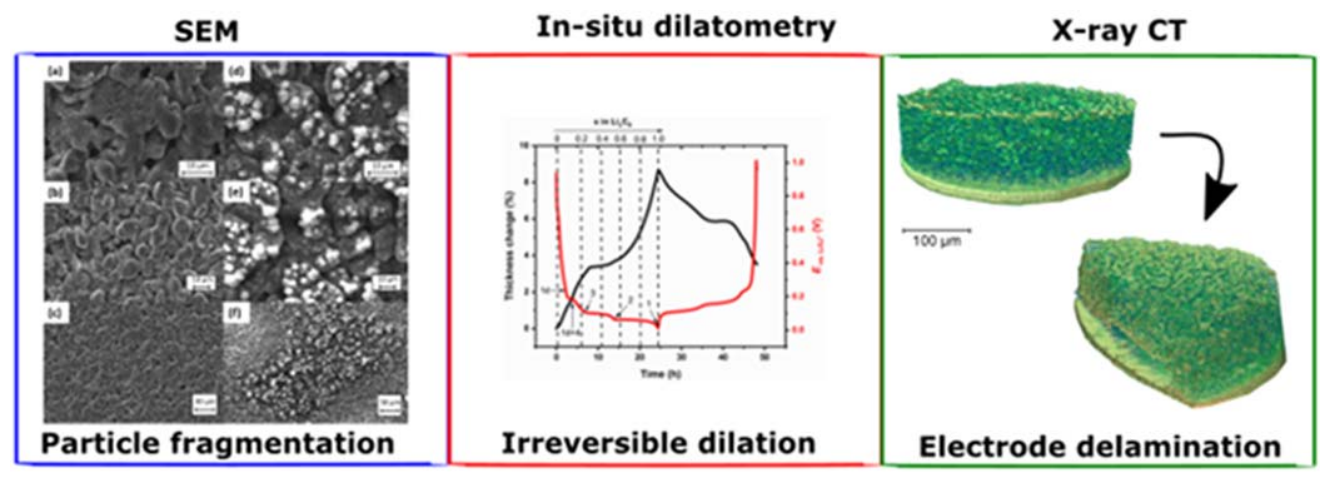

Single cycle characterisation

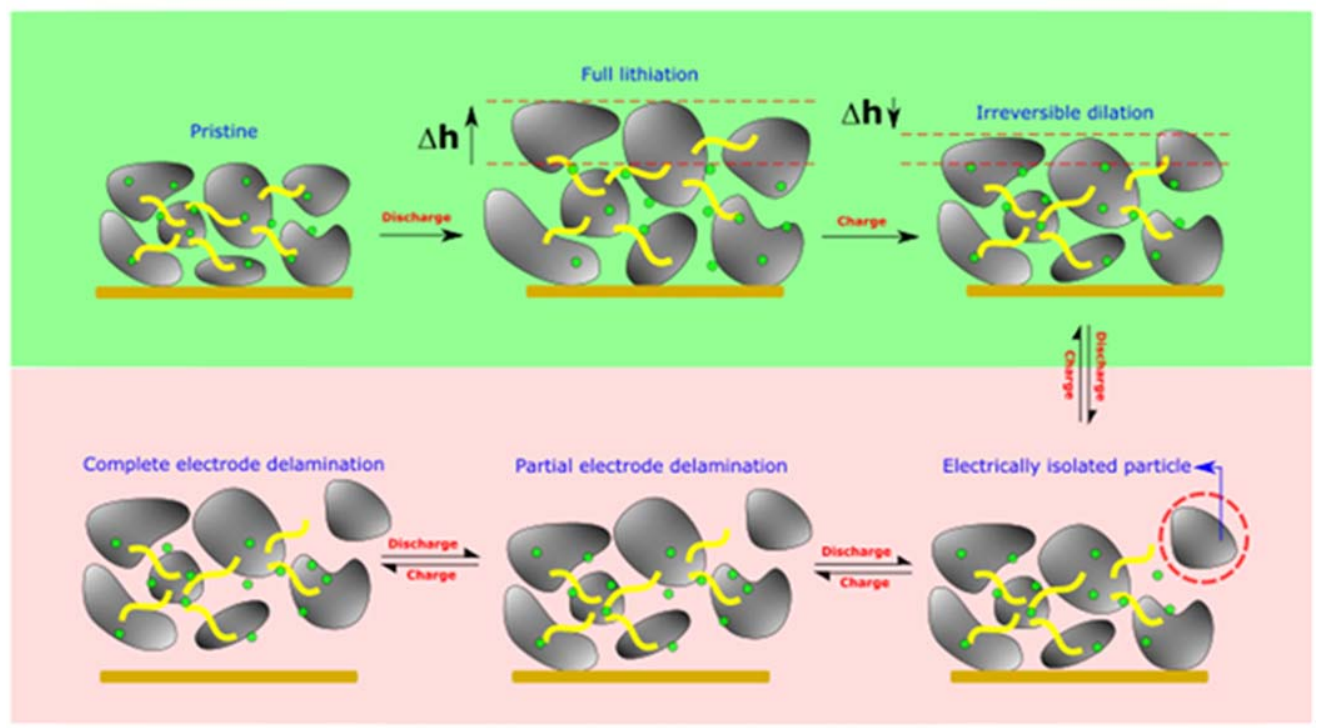

Multiple cycle characterisation

Figure 7. A schematic showing the three key techniques used with their main findings and a cartoon depicting the morphological changes that the graphite electrode can undergo as a consequence of prolonged cycling. The individual components of the electrode are represented in the following colours; graphite particles (grey), conductive additive (green), binder (yellow) and current collector (gold).

values for tortuosity and electrode pore phase volume fraction after cycling, which was expected as the electrode only underwent 20 cycles at a relatively slow C-rate of $\mathrm{C} / 8$. It would be interesting in future research to relate these changes in thickness with the SEI formation by performing some structural analysis and detailed impedance studies.

\section{Acknowledgments}

This work was supported by The Faraday Institution (faraday.ac. uk; EP/S003053/1), grant number FIRG001; and Royal Academy for Engineering CiET1718\59. Access to the lab-based X-ray instrument was supported through EP/N032888/1.

\section{ORCID}

T. M. M. Heenan (iD https://orcid.org/0000-0001-9912-4772

P. R. Shearing (10) https://orcid.org/0000-0002-1387-9531

\section{References}

1. L. Lu, X. Han, J. Li, J. Hua, and M. Ouyang, "A review on the key issues for lithium-ion battery management in electric vehicles." J. Power Sources, 226, 272 (2013).

2. R. Hausbrand, G. Cherkashinin, H. Ehrenberg, M. Groting, K. Albe, C. Hess, and W. Jaegermann, "Fundamental degradation mechanisms of layered oxide Li-ion battery cathode materials: Methodology, insights and novel approaches." Mater. Sci. Eng. B, 192, 3 (2015).
3. J. Wang, J. Purewal, P. Liu, J. H. Garner, S. Soukazian, E. Sherman, A. Sorenson, L. Vu, H. Tataria, and M. Verbrugge, "Degradation of lithium ion batteries employing graphite negatives and nickel-cobalt-manganese oxide + spinel manganese oxide positives: Part 1, aging mechanisms and life estimation." J. Power Sources, 269, 937 (2014).

4. D. Sauerteig, S. Ivanov, H. Reinshagen, and A. Bund, "Reversible and irreversible dilation of lithium-ion battery electrodes investigated by in situ dilatometry." J. Power Sources, 342, 939 (2017).

5. X. Y. Song and K. Kinoshita, "Microstructural characterization of lithiated graphite." J. Electrochem. Soc., 143, L120 (1996).

6. J. B. Siegel, A. G. Stefanopoulou, P. Hagans, Y. Ding, and D. Gorsich, "Expansion of lithium ion pouch cell batteries: observations from neutron imaging." J. Electrochem. Soc., 160, A1031 (2013).

7. M. Winter, J. O. Besenhard, M. E. Spahr, and P. Novák, "Insertion electrode materials for rechargeable lithium batteries." Adv. Mater., 10, 725 (1998).

8. S. Schweidler, L. De Biasi, A. Schiele, A. Hartmann, P. Brezesinski, and J. Janek, "Volume changes of graphite anodes revisited: a combined operando X-ray diffraction and in Situ pressure analysis study." J. Phys. Chem. C, 122, 8829 (2018).

9. J. V. Persson, M. A. Danzer, M. Bauer, M. Wachtler, and H. St, "Understanding the dilation and dilation relaxation behavior of graphite-based lithium-ion cells." J. Power Sources, 317, 93 (2016).

10. M. Winter, G. H. Wrodnigg, J. O. Besenhard, W. Biberacher, and P. Novák, “ Dilatometric investigations of graphite electrodes in nonaqueous lithium battery electrolytes." J. Electrochem. Soc., 147, 2427 (2000).

11. M. Li, Z. Wang, J. Fu, K. Ma, and E. Detsi, "In situ Electrochemical Dilatometry Study of Capacity Fading in Nanoporous Ge-Based Na-ion Battery Anodes." Scripta Materialia , 164, 52 (2019).

12. M. Li, Z. Wang, and E. Detsi, "In Situ Electrochemical Dilatometry Study of (De) lithiation and Polysulfide Dissolution-Induced Dimensional Changes in LithiumSulfur Cathodes during Charging and Discharging." J. Electrochem. Soc, 167, 050505 (2020). 
13. T. Ohzuku, N. Matoba, and K. Sawai, "Direct evidence on anomalous expansion of graphite- negative electrodes on first charge by dilatometry." J. Power Sources, 97-98, 73 (2001).

14. J. Huesker, L. Froböse, A. Kwade, M. Winter, and T. Placke, "Electrochimica acta in situ dilatometric study of the binder influence on the electrochemical intercalation of BIS(trifluoromethanesulfonyl)imide anions into graphite." Electrochim Acta, 257, 423 (2017).

15. M. Wagner, P. R. Raimann, A. Trifonova, K. C. Möller, J. O. Besenhard, and M. Winter, "Dilatometric and mass spectrometric investigations on lithium ion battery anode materials." Anal. Bioanal. Chem., 379, 272 (2004).

16. A. Yermukhambetova, C. Tan, S. R. Daemi, and Z. Bakenov, "Exploring 3D microstructural evolution in Li-Sulfur battery electrodes using in situ X-ray tomography." Nat. Publ. Gr., 6, 1 (2016).

17. A. Etiemble, J. Adriena, E. Maire, H. Idrissia, D. Reyter, and L. Roué, "3D morphological analysis of copper foams as current collectors for Li-ion batteries by means of X-ray tomography 3D morphological analysis of copper foams as current collectors for Li-ion batteries by means of X-ray tomography." Mater. Sci. Eng. B, 187, 1 (2014).

18. V. Yufit, P. Shearing, R. W. Hamilton, P. D. Lee, M. Wu, and N. P. Brandon, "Investigation of lithium-ion polymer battery cell failure using X-ray computed tomography." Electrochem. Commun., 13, 608 (2011).

19. M. Inaba, H. Yoshida, Z. Ogumi, and S. Rod, "In Situ Raman Study on Electrochemical Li Intercalation into Graphite." J. Electrochem Soc, 142, 20 (1995).

20. D. Billaud, F. X. Henry, M. Lelaurain, and P. Willmann, "Revisited structures of dense and dilute stage II lithium-graphite intercalation compounds." J. Phys. Chem. Solids, 57, 775 (1996).

21. M. Hahn, H. Buqa, P. W. Ruch, D. Goers, M. E. Spahr, J. Ufheil, P. Novák, and R. Kötz, "A dilatometric study of lithium intercalation into powder-type graphite electrodes." Electrochem. Solid-State Lett., 11, A151 (2008).

22. N. A. W. Holzwarth, S. G. Louie, and S. Rabii, "Lithium-intercalated graphite: Selfconsistent electronic structure for stages one, two, and three." Phys. Rev. B, 28, 1013 (1983).

23. T. D. Tran, J. H. Feikert, R. W. Pekala, and K. Kinoshita, "Rate effect on lithiumion graphite electrode performance." J. Appl. Electrochem., 26, 1161 (1996).

24. J. R. Dahn, "Phase diagram of Li $\mathrm{i}_{\mathrm{xC} 6}$." Phys. Rev. B, 44, 9170 (1991).

25. Z. Peng, T. W. Yang, Z. J. Li, Z. H. Li, Q. L. Jin, and R. Zhou, "Tensile propertie and anisotropy of ordered porous copper." J. Nonferrous Met., 21, 1045 (2011)

26. H. He, C. Huang, C. W. Luo, J. J. Liu, and Z. S. Chao, "Dynamic study of Li intercalation into graphite by in situ high energy synchrotron XRD." Electrochim. Acta, 92, 148 (2013)

27. B. Rieger, S. Schlueter, S. V. Erhard, J. Schmalz, G. Reinhart, and A. Jossen, "Multi-scale investigation of thickness changes in a commercial pouch type lithiumion battery." J. Energy Storage, 6, 213 (2016)

28. R. Yazami and Y. Reynier, "Thermodynamics and crystal structure anomalies in lithium- intercalated graphite." J. Power Sources, 153, 312 (2006).

29. D. Y. W. Yu, M. Zhao, and H. E. Hoster, "Suppressing vertical displacement of lithiated silicon particles in high volumetric capacity battery electrodes." ChemElectroChem., 2, 1090 (2015).

30. E. M. C. Jones, Çapraz, S. R. White, and N. R. Sottos, "Reversible and irreversible deformation mechanisms of composite graphite electrodes in lithium-ion batteries..' J. Electrochem. Soc., 163, A1965 (2016).
31. S. Hein et al., "Influence of conductive additives and binder on the impedance of lithium-ion battery electrodes: effect of morphology." J. Electrochem. Soc., 167, 013546 (2020).

32. Z. Chen, L. Christensen, and J. R. Dahn, "A study of the mechanical and electrical properties of a polymer/carbon black binder system used in battery electrodes." J. Appl. Polym. Sci., 90, 1891 (2003).

33. E. M. C. Jones, M. N. Silberstein, S. R. White, and N. R. Sottos, "In situ measurements of strains in composite battery electrodes during electrochemical cycling." Exp. Mech., 54, 971 (2014).

34. J. F. Gonzalez, K. Sun, M. Huang, J. Lambros, and S. Dillon, "Three-dimensiona study of graphite-composite electrode chemo-mechanical response using digital volume correlation." Exp. Mech., 58, 573 (2018).

35. M. Goktas, C. Bolli, E. J. Berg, P. Novák, K. Pollok, F. Langenhorst, M. Roeder, O. Lenchuk, D. Mollenhauer, and P. Adelhelm, "Graphite as cointercalation electrode for sodium-ion batteries: electrode dynamics and the missing solid electrolyte interphase (SEI)." Adv. Energy Mater., 1702724, 1 (2018).

36. B. Key, M. Morcrette, J. M. Tarascon, and C. P. Grey, "Pair distribution function analysis and solid state NMR studies of silicon electrodes for lithium ion batteries: Understanding the (de)lithiation mechanisms." J. Am. Chem. Soc., 133, 503 (2011).

37. C. Uhlmann, J. Illig, M. Ender, R. Schuster, and E. Ivers-Tiffée, "In situ detection of lithium metal plating on graphite in experimental cells." J. Power Sources, 279, 428 (2015)

38. N. Legrand, B. Knosp, P. Desprez, F. Lapicque, and S. Raël, "Physica characterization of the charging process of a Li-ion battery and prediction of $\mathrm{Li}$ plating by electrochemical modelling." J. Power Sources, 245, 208 (2014).

39. P. K. Nayak, L. Yang, K. Pollok, and F. Langenhorst, "Investigation of $\mathrm{Li}_{1.17} \mathrm{Ni}_{0.20} \mathrm{Mn}_{0.53} \mathrm{Co}_{0.10} \mathrm{O}_{2}$ as an Interesting Li- and Mn-Rich Layered Oxide Cathode Material through Electrochemistry, Microscopy, and In Situ Electrochemical Dilatometry." ChemElectroChem, 6, 2812 (2019).

40. C. Chen, C. Pan, W. Su, J. Rick, and C. Wang, "Operando X-ray diffraction and Xray absorption studies of the structural transformation upon cycling excess $\mathrm{Li}$ layered oxide $\mathrm{Li}\left[\mathrm{Li}_{1 / 18} \mathrm{Co}_{1 / 6} \mathrm{Ni}_{1 / 3} \mathrm{Mn}_{4 / 9}\right] \mathrm{O}_{2}$ in $\mathrm{Li}$ ion batteries." J. Mater. Chem. A., 2, 8613 (2015)

41. R. Fong, "Studies of lithium intercalation into carbons using nonaqueous electrochemical cells." J. Electrochem. Soc., 137, 2009 (1990).

42. J. Vetter, P. Novák, M. R. Wagner, C. Veit, K. C. Möller, J. O. Besenhard, M. Winter, M. Wohlfahrt-Mehrens, C. Vogler, and A. Hammouche, "Ageing mechanisms in lithium-ion batteries." J. Power Sources, 147, 269 (2005).

43. W. Gu, Z. Sun, X. Wei, and H. Dai, "A capacity fading model of lithium-ion battery cycle life based on the kinetics of side reactions for electric vehicle applications." Electrochim. Acta, 133, 107 (2014).

44. O. O. Taiwo, D. P. Finegan, J. Gelb, C. Holzner, D. J. L. Brett, and P. R. Shearing, "The use of contrast enhancement techniques in X-ray imaging of lithium-ion battery electrodes." Chem. Eng. Sci., 154, 27 (2016).

45. S. R. Daemi, C. Tan, T. Volkenandt, S. J. Cooper, A. Palacios-Padros, J. Cookson, D. J. L. Brett, and P. R. Shearing, "Visualizing the carbon binder phase of battery electrodes in three dimensions." ACS Appl. Energy Mater., 1, 3702 (2018).

46. Y. K. Chen-wiegart, R. Demike, C. Erdonmez, K. Thornton, S. A. Barnett, and J. Wang, "Tortuosity characterization of 3D microstructure at nano-scale for energy storage and conversion materials." J. Power Sources, 249, 349 (2014).

47. S. J. Cooper, A. Bertei, P. R. Shearing, J. A. Kilner, and N. P. Brandon, "Sciencedirect taufactor: an open-source application for calculating tortuosity factors from tomographic data." SoftwareX, 5, 203 (2016). 